\title{
Neutrophils and macrophages: the main partners of phagocyte cell systems
}

\author{
Manuel T. Silva ${ }^{1 \dagger}$ and Margarida Correia-Neves ${ }^{2,3} *$ \\ ${ }^{1}$ Instituto de Biologia Molecular e Celular (IBMC), Universidade do Porto, Porto, Portugal \\ ${ }^{2}$ Life and Health Sciences Research Institute (ICVS), School of Health Sciences, University of Minho, Braga, Portugal \\ ${ }^{3}$ ICVS/3B's - PT Government Associate Laboratory, Braga/Guimarães, Portugal
}

Edited by:

Andrea Cooper, Trudeau Institute, USA

Reviewed by:

Renee M. Tsolis, University of California-Davis, USA

Alice Nyakeriga, Texas Tech

University, USA

\section{${ }^{*}$ Correspondence:}

Margarida Correia-Neves, Life and Health Sciences Research Institute (ICVS), School of Health Sciences, University of Minho, Campus de Gualtar, 4710-057

Braga, Portugal. e-mail:

mcorreianeves@ecsaude.uminho.pt

${ }^{\dagger}$ This prospective article was written by Manuel T. Silva. Margarida

Correia-Neves had several

enthusiastic discussions on the

subject during the preparation of the manuscript. Given the untimely death of the author Manuel T. Silva in April 2012, Margarida Correia-Neves took over the submission process of the manuscript.
Biological cellular systems are groups of cells sharing a set of characteristics, mainly key function and origin. Phagocytes are crucial in the host defense against microbial infection. The previously proposed phagocyte cell systems including the most recent and presently prevailing one, the mononuclear phagocyte system (MPS), grouped mononuclear cells but excluded neutrophils, creating an unacceptable situation. As neutrophils are archetypical phagocytes that must be members of comprehensive phagocyte systems, Silva recently proposed the creation of a myeloid phagocyte system (MYPS) that adds neutrophils to the MPS. The phagocytes grouped in the MYPS include the leukocytes neutrophils, inflammatory monocytes, macrophages, and immature myeloid DCs. Here the justifications behind the inclusion of neutrophils in a phagocyte system is expanded and the MYPS are further characterized as a group of dedicated phagocytic cells that function in an interacting and cooperative way in the host defense against microbial infection. Neutrophils and macrophages are considered the main arms of this system.

Keywords: phagocyte systems, microbial infections, neutrophils, monocytes, macrophages, DCs

\section{INTRODUCTION}

When infectious agents pass the peripheral defenses and invade sterile body territories they face innate antimicrobial mechanisms. The pathological result of the presence of a microbe within a host is dependent on the virulence of the pathogen and on the defense competence of the host (Finlay and Falkow, 1989; Casadevall and Pirofski, 2001). When functioning as a pathogen, the infectious agent is living from its pathogenicity, but when the host antimicrobial protective mechanisms dominate there is the efficient protective intervention of several immune and non-immune cells. This intervention is crucially centered on the antimicrobial activities of phagocyte cells, mainly macrophages and neutrophils. Although epithelial cells, fibroblasts, and other cells can phagocytose, in this text the term phagocytes is used for cells whose main function is phagocytosis and that have been classically called professional or dedicated phagocytes, namely neutrophils, inflammatory monocytes, macrophages, and immature dendritic cells (DCs).

Phagocytosis is the process by which eukaryotic cells engulf large particles $(>0.5 \mu \mathrm{m})$ including prokaryotic and eukaryotic cells. When functioning as a microbe-killing mechanism, phagocytosis triggers rich antimicrobial processes that use a large array of mechanisms involving oxidants like reactive oxygen/nitrogen species (ROS, RNS), granule proteins, and iron-withholding molecules (reviewed in Flannagan et al., 2009). Although phagocytes operate using phagocytic and non-phagocytic mechanisms (Silva, 2010a,b), phagocytosis is the activity that confers their typical character.

\section{METCHNIKOFF, PHAGOCYTES, AND PHAGOCYTOSIS}

While lower eukaryotes use phagocytosis mainly for the acquisition of nutrients, phagocytosis in metazoans is primarily carried out by the specialized professional phagocytes, macrophages, and neutrophils, for a wide range of tasks that include, but are not restricted to, uptake and destruction of invading pathogens (Dale et al., 2008; Cassatella et al., 2009; Silva, 2010a,b).

Although the uptake of particles by cells has been reported before, Metchnikoff, stimulated by Carl Claus, introduced the term "phagocyte," and the theory of phagocytosis and phagocytic cells is a fundamental contribution by Metchnikoff. His seminal observations behind the phagocytosis theory are extensively discussed in two publications translated to English (Metchnikoff, $1893,1905)$ and in biographic texts (see for example Tauber, 2003; Kaufmann, 2008). Metchnikoff understood that phagocytosis represents a central defense mechanism of the host against microbial invaders. The main roots of the theory of phagocytic cells originated from the initial observations made in starfish larva and later in vertebrates. In 1984, working with natural yeast 
infection in Daphnia, he reported on the antimicrobial activity of phagocytes. In 1887, he described the two types of professional phagocytes in vertebrates, macrophages and neutrophils, the latter initially called "microphages" (Metchnikoff, 1893). Another important Metchnikoff's contribution to the field of phagocytosis was the understanding that the lamprey's larvae (ammocoetes) was the lowest biological entity where macrophages and neutrophils coexisted (Metchnikoff, 1905).

The morphological antinomy macrophage/microphage originated by Metchnikoff, based on the differences in morphological size of the two phagocytes (Metchnikoff, 1893), does not have a corresponding parallel with respect to their function. Indeed, when considering the roles of the two phagocytes against microbial infection, Metchnikoff calls neutrophils "principal combatants" and throughout his publications and lectures he stressed that both macrophages and neutrophils were important players: "Phagocytosis is exhibited not only by the macrophages but also, in a high degree, by the microphages which stand out as the defensive cells par excellence against microorganisms" (Metchnikoff, 1905).

\section{NEUTROPHILS: ARCHETYPES OF PHAGOCYTE CELLS}

In spite of the importance Metchnikoff attributed to neutrophils as a phagocyte archetype, the post-Metchnikoff evolving trend was to consider macrophages the essential phagocytes minimizing the importance of neutrophils. This macrophage-centric view was reflected in the exclusion of the neutrophil in the initial attribution, in 1967, of the label "professional phagocytes" to macrophages (Rabinovitch, 1967) and in the creation of systems of phagocytic cells that excluded the neutrophil (Aschoff, 1924; Volterra, 1927; van Furth et al., 1972). This cell was considered at the time a terminally differentiated phagocyte with very limited functional capacities. However, the evolution of knowledge about phagocytes progressively led to a new concept of neutrophils as archetypical phagocytic and modulator immune cells, with an origin common to that of the macrophages (Cassatella, 1995, 1999; Rabinovitch, 1995; Akashi et al., 2000; Cassatella et al., 2009; Borregaard, 2010; Silva, 2010b; Costantini and Cassatella, 2011; Mantovani et al., 2011). This new perspective of the neutrophil highlighted novel unexpected capabilities for this essential component of the immune system, which is still under further study nowadays.

Although varying among mammals, the antimicrobial capacity of neutrophils is higher than that of macrophages (Levy, 2004; Segal, 2005). Neutrophils are equipped with a huge assortment of microbicidal mechanisms and use multiple antimicrobial molecules stored in enormous amounts in granules (Borregaard and Cowland, 1997; Segal, 2005). Production of ROS is most prominent in neutrophils as compared with macrophages (Nathan and Shiloh, 2000). Several antimicrobial proteins that are an important part of the neutrophil arsenal are lacking or scarce in the tissue macrophage (Levay and Viljoen, 1995; Lehrer and Ganz, 2002; Selsted and Ouellette, 2005). This is the case of defensins and cathelicidins, the major families of mammalian antimicrobial peptides of neutrophils (Ganz, 2003), and of lactoferrin (Levay and Viljoen, 1995). The bactericidal/permeability-increasing protein (BPI) is also specific of neutrophils (Weiss and Olsson, 1987).
Myeloperoxidase (MPO), which is an important enzyme involved in oxidative antimicrobial mechanisms of neutrophils, is present in circulating mammal monocytes but is lost as these mature into macrophages (Klebanoff, 2005), which correlates with decay in antimicrobial activity (Locksley et al., 1987).

\section{PHAGOCYTE CELL SYSTEMS}

Biological cellular systems are groups of cells that share common features, mostly function and origin (Aschoff, 1924; van Furth et al., 1972). Following the pioneer studies by Metchnikoff several systems of phagocytic cells have been created and, strangely, all these were confined to mononuclear cells and excluded neutrophils. One argument used in the proposal of these mononuclear systems was that Metchnikoff considered macrophages as the major phagocytic cells, an interpretation that, as discussed above, is not justified. Aschoff (1924) created the "reticuloendothelial system" (RES), formed by mononuclear cells with presumed phagocytic capacity but neutrophils were left outside for not being considered major phagocytes (Aschoff, 1924). Following progressive criticisms to the previous systems, the "mononuclear phagocyte system" (MPS) was created in 1969 based on a proposal by van Furth and coworkers at a Conference dedicated to Mononuclear Phagocytes. This proposal was formally published (van Furth et al., 1972) and described the MPS as a system of dedicated phagocytic cells with similar morphology, function, origin and kinetics, grouping monocytes/macrophages, and their precursors but again excluding neutrophils. This exclusion was based on the argument that "although polymorphonuclear phagocytes are mononuclear too, they belong to another cell line because of their different origin and divergent kinetic and functional behavior" (van Furth et al., 1972). When the MPS was proposed, knowledge on myelogenesis was limited and the common origin of neutrophils and macrophages was not known, the neutrophils being considered to belong to a cell line separated from that of the MPS members and to be a terminally differentiated phagocytic effector with limited kinetic and functional capacities.

Comprehensive phagocyte cell systems must include neutrophils and Silva recently proposed an enlarged system grouping dedicated phagocytic cells including neutrophils (Silva, 2010a). All dedicated phagocytes are of the myeloid lineage (Figure 1) as they originate in the "common myeloid progenitors" (CMPs) via the "granulocyte/macrophage lineage-restricted progenitors" (GMPs; Akashi et al., 2000; Iwasaki and Akashi, 2007). Thus, the new system was labeled myeloid phagocyte system (MYPS; Silva, 2010a). Here the justifications for such proposal are extended and the MYPS are further characterized focusing on human and mouse studies.

\section{THE MEMBERS OF THE MYPS}

The leukocytes of the MYPS share origin, avid phagocytic abilities, and kinetics. Regarding their morphology, the precursor forms of all members of the MYPS are similar except for the mature circulating neutrophil. Mature neutrophils are mononuclear like the other members of the MYPS but the terminal mature form is morphologically differentiated and has a polylobed nucleus. This has been considered as a structural 


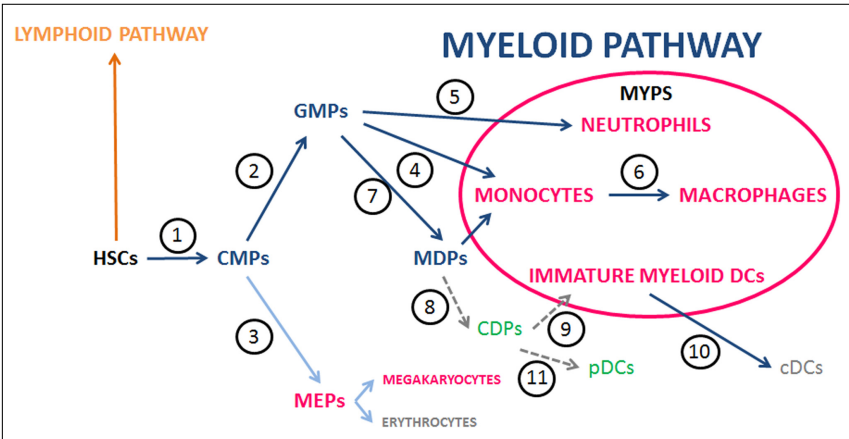

FIGURE 1 | Main steps and players of myelopoiesis in the context of the MYPS. Graph depicting one interpretation of the still evolving view of the myelopoiesis pathways (blue arrows) associated with the poiesis of the members of the MYPS in mice and humans. This interpretation takes into consideration recent publications whose references are given below (see also the reviews Friedman, 2002; Iwasaki and Akashi, 2007; Varol et al., 2009; Geissmann etal., 2010b). HSCs give rise to CMPs (1) (Akashi et al., 2000: Manz et al., 2002). CMPs originate GMPs (2) and MEPs (3) (Akashi etal., 2000; Manz et al., 2002). GMPs differentiate into Monocytes (4), Eosinophils, Basophils, Mast cells, and Neutrophils (5) (Akashi et al., 2000; Iwasaki and Akashi, 2007) and MDPs (7) (Iwasaki and Akashi, 2007). An alternative to the view that MDPs originate from GMPs considered that MDPs would directly derive from CMPs; Fogg et al., 2006). Monocytes mature into Macrophages (6) (van Furth et al., 1973; Akashi et al., 2000; Sunderkotter etal., 2004; Fogg etal., 2006). The pathways to myeloid DCs include MDPs [originated from GMPs (7); Iwasaki and Akashi, 2007] that differentiate into CDPs (8) (Onai et al., 2007; Liu et al., 2009) and these give rise to Immature myeloid DCs (9) [that originate cDCs (10)], and pDCs (11) (Naik etal., 2006, 2007). The members of the MYPS are highlighted in bold. MYPS, myeloid phagocyte system; HSCs, hematopoietic stem cells; CMPs, common myeloid precursors; GMPs, granulocyte/macrophage precursors; MEPs, megakaryocyte/erythrocyte progenitors; MDPs, macrophage/DC progenitors; CDPs, common DC progenitors; cDCs, conventional (or classic) myeloid DCs; pDCs, plasmacytoid DCs.

specialization that facilitates the mechanical deformation, allowing neutrophils to "squeeze" through tight spaces when moving to inflammatory/infectious foci.

The list of MYPS members proposed below may have to be altered according to the continuously evolving knowledge in this area. This is particularly relevant for DCs since they share to a great extent the origin and function of other cell members of the MYPS. Of notice, all except neutrophils are antigen-presenting cells. However, since the concept of MYPS, as it stands presently, requires a high phagocytic profile, among the DC cell populations, only immature myeloid DCs were included.

\section{NEUTROPHILS}

All granulocytes are phagocytic but neutrophils (mouse and human key markers: CD66b, LY6-G) are the only exhibiting avid phagocytosis. As already stressed, neutrophils have been acquiring a progressive status of fundamental phagocytic immune cells (Cassatella, 1995, 1999; Rabinovitch, 1995; Cassatella et al., 2009; Borregaard, 2010; Silva, 2010b; Costantini and Cassatella, 2011; Mantovani et al., 2011) with phagocytic abilities superior to those of macrophages (see Section Neutrophils: archetypes of phagocyte cells). Comprehensive reviews on these leukocytes include recent contributions (Nathan, 2006; Nauseef, 2007; Dale et al., 2008; Borregaard, 2010).

\section{INFLAMMATORY MONOCYTES}

Inflammatory monocytes constitute a heterogeneous group of macrophage progenitors and have been divided into two main subsets: a short-lived "inflammatory subset" (key markers; mouse: CD11b, F4/80, Ly6 C; human: CD11b, LY6C) that homes to inflamed tissue, and a "resident subset," with a longer half-life, that homes to non-inflamed tissues (Geissmann et al., 2003). Inflammatory monocytes are phagocytic and use this capacity as an antimicrobial mechanism (Grage-Griebenow et al., 2001; Sunderkotter et al., 2004; Serbina et al., 2008; Soehnlein et al., 2008c).

\section{MACROPHAGES}

Macrophages (key markers; mouse: CD11b (Mac-1), F4/80; human: CD33) have remarkable phagocytic abilities that largely surpass their contribution to direct antimicrobial host mechanisms of defense. Many recent comprehensive reviews on these phagocytes are available (Hume, 2006; Mosser and Edwards, 2008; Serbina et al., 2008; Pluddemann et al., 2011).

\section{IMMATURE MYELOID DCs}

Dendritic cells (Steinman and Banchereau, 2007) were not included in the MPS based in part on the interpretation that they "are not highly phagocytic" (van Furth et al., 1972). They are a group of primarily antigen presenting and immunomodulatory cells whose distinctiveness has been debated (Hume, 2008; Geissmann et al., 2010a). Mature DCs are not considered dedicated phagocytes and have not been included in the group of professional phagocytes (Rabinovitch, 1995). Mature DCs have a limited capacity for lysosomal degradation of ingested material (Delamarre et al., 2005) and, in contrast to neutrophils and macrophages, are not involved in direct pathogen clearance (Savina and Amigorena, 2007). On the other hand, immature myeloid DCs are phagocytic (Inaba et al., 1993b; Steinman and Swanson, 1995) and have direct effector antimicrobial activities (Banchereau and Steinman, 1998; Banchereau et al., 2000). Thus, they are included as members of the MYPS.

\section{NEUTROPHILS AS ESSENTIAL MEMBERS OF PHAGOCYTE CELL SYSTEMS}

Several arguments justify the inclusion of neutrophils in any comprehensive phagocyte cell system, as follows.

1. Neutrophils are archetypical phagocytes: As referred before, the exclusion of neutrophils from the MPS was based on the interpretation that their origin and kinetic and functional behavior are different from those of monocytes/macrophages, interpretation that, with the advances in knowledge, has been proved incorrect.

2. Neutrophils, monocytes/macrophages and immature myeloid DCs have a common origin: The initial view that neutrophils and macrophages arise from a common late bone marrow precursor (Metcalf, 1989; Inaba et al., 1993a) has been confirmed by results showing that these phagocytes originate from hematopoietic stem cells (HSC) which differentiate through common pathways that also lead to immature myeloid DCs (Akashi et al., 2000; Iwasaki and Akashi, 2007; Figure 1).

3. Macrophages and neutrophils share important features: Important features shared by macrophages and neutrophils with 
respect to their common origin include: (i) avid phagocytic capabilities (Dale et al., 2008); (ii) presence of common surface markers like chemokine receptors (Silva, 2010a) and receptors for Igs and complement (Dale et al., 2008), and common patterns of cytokine and chemokine secretion (Silva, 2010a); (iii) common expression of pattern recognition receptors (PRR) (Janeway, 1989); (iv) cooperative participation in the orchestration of adaptive immune responses (Silva, 2010b); (v) scavenger capacity [while macrophages are the main scavenger phagocyte (Parnaik etal., 2000), neutrophils may function as a backup system when the scavenging capacity of macrophages is overwhelmed in situations of hyper-inflammation (RydellTormanen etal., 2006)]; (vi) similarity on the kinetic behavior under inflammatory/infectious conditions (Silva, 2010a). Also to consider are reports on the possible conversion of neutrophils into macrophages (Araki etal., 2004; Sasmono et al., 2007). Additionally, two functional criteria that were taken into consideration to select cells to be grouped in the MPS, namely pinocytosis and the ability to attach firmly to a glass surface (van Furth etal., 1972), are now known to be exhibited by neutrophils as well (Hoffstein etal., 1981; Davis et al., 1986).

4. Macrophage/neutrophil functional partnership: The cooperation between the members of a cell system enhances its functional efficiency (Seeley, 2002; Shou et al., 2007). Data discussed above and elsewhere (Silva, 2010a,b, 2011) indicate that the MYPS is an assembly of dedicated phagocytic cells that function in an interacting and cooperative way.

While sharing several functions, macrophages and neutrophils are specialized cells with functional and function-related morphological distinctive features. These features are complementary and provide varied levels of antimicrobial capacities and cytotoxicity, and tissue-specific localization and lifespan (Silva, 2010a). These distinctive features explain why macrophages and neutrophils are not able to replace each other as central players of antimicrobial immunity, as indicated by the pathology associated with some human and murine phagocyte deficiencies (Dale and Liles, 2002).

The combination of shared and complementary features of macrophages and neutrophils promotes their cooperative participation as effectors and modulators in immunity against infection (Silva, 2010a,b). This cooperation is clearly illustrated by the ability of macrophages, in their process of killing intracellular bacteria, to take up proteins and peptides (e.g., human neutrophil peptide 1) produced and released by neutrophils. In addition, macrophages are also able to engulf apoptotic neutrophils and make use of the antimicrobial molecules present in their granules. Based on these results (Silva et al., 1989; Sharma et al., 2000; Tan et al., 2006; Sawant et al., 2010), in 2009 Silva proposed the concept of macrophage/neutrophil partnership in the host response against infection (Silva, 2010a), a concept extensively reviewed in Silva (2011).

The framework of the concept of macrophage/neutrophil partnership (Silva, 2010a,b, 2011), which is a central facet of the MYPS system, includes several cooperative macrophage/neutrophil activities. (i) At the initiation of the infectious inflammation, complex networks of cytokines and chemokines originate through interaction of monocytes/macrophages and neutrophils at the infectious/inflammatory foci (Silva, 2010a; Soehnlein and Lindbom, 2010). (ii) Amplification of the limited antimicrobial capacity of macrophages by the acquisition of neutrophil potent microbicidal molecules without transit as extracellular damage associated molecular pattern molecules (DAMPs), thus reducing the harm due to excessive inflammation (Silva et al., 1989; Silva, 2010a). In situations where macrophages handle diverse intramacrophage microbes in different ways, antimicrobial components of neutrophil granules, acquired by macrophages through uptake of neutrophils or neutrophil granules, are mobilized to the diverse types of microbe-containing vacuoles (Silva, 2011). At these locations the acquired molecules may exert their antimicrobial role through a direct activity against the intramacrophage pathogens (Sharma et al., 2000; Tan et al., 2006) or through interaction with the endogenous macrophage antimicrobial mechanisms (Lincoln et al., 1995; Marodi et al., 1998). (iii) A non-phagocytic facet of the interactive cooperation macrophage/neutrophil at the effector level is the reciprocal activation of monocytes/macrophages and neutrophils. Monocytes/macrophages can be activated directly by neutrophil products, including released granule molecules, with boosting of their phagocytic and antimicrobial capacities (Lima and Kierszenbaum, 1985; Ichinose et al., 1996; Zughaier et al., 2005; Soehnlein et al., 2008a,b,c) and neutrophils are activated by macrophage-secreted cytokines and chemokines and acquire an inflammatory effector phenotype (reviewed in Silva, 2010a). (iv) Interaction and cooperation results in the resolution of the infectious inflammation upon control of the infectious process, as well (Silva, 2010a; Soehnlein and Lindbom, 2010). A similar concept was proposed after the initial paper by Silva (Soehnlein and Lindbom, 2010).

This cooperative partnership represents a factor for increased efficiency of the MYPS. As already noted by Metchnikoff (1905), the presence of two professional phagocytes is exclusive of the immune system of vertebrates. The cooperation macrophage/neutrophil within the competences of the MYPS, allows an immune attack strategy against microbial infections based on two complementary phagocytes that safely take advantage of powerful neutrophil microbicidal factors that are transferred to the infected macrophage. This is a safe way of macrophages to make use of powerful but dangerous microbicidal molecules avoiding the problems of permanently carrying these cytotoxic factors. This strategy is a target of key virulence mechanisms of successful pathogens.

\section{CONCLUSION}

Based on the principle that phagocyte cell systems must include all dedicated phagocytic cells, the creation of the MYPS (Silva, 2010a) was proposed, changing the unacceptable prevailing situation where the only phagocyte cell system in use (MPS) excludes neutrophils. The members of this system have common origin and share avid phagocytic abilities. Besides individual activities of the members of a cellular system, cooperation between them enhances the system's functional efficiency. Macrophage/neutrophil partnership, important in phagocytic, immunomodulatory, and inflammation pro-resolving activities, 
is particularly relevant in the operation of the MYPS (Silva, 2010a). Thus, neutrophils and macrophages are the main arms of this system.

In conclusion, the MYPS is a system of dedicated phagocytic cells that groups neutrophils, inflammatory monocytes, macrophages, and immature myeloid DCs; these functions in

\section{REFERENCES}

Akashi, K., Traver, D., Miyamoto, T., and Weissman, I. L. (2000). A clonogenic common myeloid progenitor that gives rise to all myeloid lineages. Nature 404, 193-197.

Araki, H., Katayama, N., Yamashita, Y., Mano, H., Fujieda, A., Usui, E., Mitani, H., Ohishi, K., Nishii, K., Masuya, M., Minami, N., Nobori, T., and Shiku, H. (2004). Reprogramming of human postmitotic neutrophils into macrophages by growth factors. Blood 103, 2973-2980.

Aschoff, L. (1924). "Reticuloendothelial system," in Lectures on Pathology. NY: Paul B. Hoeber, Inc.

Banchereau, J., Briere, F., Caux, C., Davoust, J., Lebecque, S., Liu, Y. J., Pulendran, B., and Palucka, K. (2000). Immunobiology of dendritic cells. Annu. Rev. Immunol. 18, 767-811.

Banchereau, J., and Steinman, R. M. (1998). Dendritic cells and the control of immunity. Nature 392, 245-252.

Borregaard, N. (2010). Neutrophils, from marrow to microbes. Immunity 33, 657-670.

Borregaard, N., and Cowland, J. B. (1997). Granules of the human neutrophilic polymorphonuclear leukocyte. Blood 89, 3503-3521.

Casadevall, A., and Pirofski, L. (2001). Host-pathogen interactions: the attributes of virulence. J. Infect. Dis. 184, 337-344.

Cassatella, M. A. (1995). The production of cytokines by polymorphonuclear neutrophils. Immunol. Today 16, 21-26.

Cassatella, M. A. (1999). Neutrophilderived proteins: selling cytokines by the pound. Adv. Immunol. 73, 369-509.

Cassatella, M. A., Locati, M., and Mantovani, A. (2009). Never underestimate the power of a neutrophil Immunity 31, 698-700.

Costantini, C., and Cassatella, M. A. (2011). The defensive alliance between neutrophils and NK cells as a novel arm of innate immunity. $J$ Leukoc. Biol. 89, 221-233.

Dale, D., and Liles, W. (2002). "Neutrophils and Monocytes: normal physiology and disorders of neutrophil and monocyte production," in
Blood: Priciples and Practice of Hematology, eds R. I. Handin, S. E. Lux, and T. P. Stossel (New York: Lippincott Williams \& Wilkins), 455-482.

Dale, D. C., Boxer, L., and Liles, W. C. (2008). The phagocytes: neutrophils and monocytes. Blood 112, 935-945.

Davis, B. H., McCabe, E., and Langweiler, M. (1986). Characterization of f-Met-Leu-Phe-stimulated fluid pinocytosis in human polymorphonuclear leukocytes by flow cytometry. Cytometry 7, 251-262.

Delamarre, L., Pack, M., Chang, H., Mellman, I., and Trombetta, E. S. (2005). Differential lysosomal proteolysis in antigen-presenting cells determines antigen fate. Science 307, 1630-1634.

Finlay, B. B., and Falkow, S (1989). Common themes in microbial pathogenicity. Microbiol. Rev. 53, 210-230.

Flannagan, R. S., Cosio, G., and Grinstein, S. (2009). Antimicrobial mechanisms of phagocytes and bacterial evasion strategies. Nat. Rev. Microbiol. 7, 355-366.

Fogg, D. K., Sibon, C., Miled, C. Jung, S., Aucouturier, P., Littman, D. R., Cumano, A., and Geissmann, F. (2006). A clonogenic bone marrow progenitor specific for macrophages and dendritic cells. Science 311 , 83-87.

Friedman, A. D. (2002). Transcriptional regulation of granulocyte and monocyte development. Oncogene $21,3377-3390$.

Ganz, T. (2003). Defensins: antimicrobial peptides of innate immunity. Nat. Rev. Immunol. 3, 710-720.

Geissmann, F., Gordon, S., Hume, D. A., Mowat, A. M., and Randolph, G. J. (2010a). Unravelling mononuclear phagocyte heterogeneity. Nat. Rev. Immunol. 10, 453-460.

Geissmann, F., Manz, M. G., Jung, S., Sieweke, M. H., Merad, M., and Ley, K. (2010b). Development of monocytes, macrophages, and dendritic cells. Science 327, 656-661.

Geissmann, F., Jung, S., and Littman, D. R. (2003). Blood monocytes consis of two principal subsets with distinct migratory properties. Immunity 19 $71-82$.

Grage-Griebenow, E., Zawatzky, R., Kahlert, H., Brade, L., Flad, H., and Ernst, M. (2001). Identification

an interacting and cooperative way in the host defense against microbial infection.

\section{ACKNOWLEDGMENTS}

Anabela Costa and José Pestana provided important editorial assistance.

of a novel dendritic cell-like subset of CD64(+)/CD16(+) blood monocytes. Eur. J. Immunol. 31, 48-56.

Hoffstein, S. T., Weissmann, G., and Pearlstein, E. (1981). Fibonectin is a component of the surface coat of human neutrophils. J. Cell Sci. 50, 315-327.

Hume, D. A. (2006). The mononuclear phagocyte system. Curr. Opin. Immunol. 18, 49-53.

Hume, D. A. (2008). Macrophages as $\mathrm{APC}$ and the dendritic cell myth. $J$ Immunol. 181, 5829-5835.

Ichinose, M., Asai, M., Imai, K., and Sawada, M. (1996). Enhancement of phagocytosis by corticostatin I (CSI) in cultured mouse peritoneal macrophages. Immunopharmacology 35, 103-109.

Inaba, K., Inaba, M., Deguchi, M., Hagi, K., Yasumizu, R., Ikehara, S. Muramatsu, S., and Steinman, R. M. (1993a). Granulocytes, macrophages, and dendritic cells arise from a common major histocompatibility complex class II-negative progenitor in mouse bone marrow. Proc. Natl. Acad. Sci. U.S.A. 90, 3038-3042.

Inaba, K., Inaba, M., Naito, M., and Steinman, R. M. (1993b). Dendritic cell progenitors phagocytose particulates, including bacillus CalmetteGuerin organisms, and sensitize mice to mycobacterial antigens in vivo. J. Exp. Med. 178, 479-488.

Iwasaki, H., and Akashi, K. (2007). Myeloid lineage commitment from the hematopoietic stem cell. Immunity 26, 726-740.

Janeway, C. A. Jr. (1989). Approaching the asymptote? Evolution and revolution in immunology. Cold Spring Harb. Symp. Quant. Biol. 54(Pt 1), $1-13$.

Kaufmann, S. H. (2008). Immunology's foundation: the 100-year anniversary of the Nobel Prize to Paul Ehrlich and Elie Metchnikoff. Nat. Immunol. 9, 705-712.

Klebanoff, S. J. (2005). Myeloperoxidase: friend and foe. J. Leukoc. Biol. 77, 598-625.

Lehrer, R. I., and Ganz, T. (2002). Cathelicidins: a family of endogenous antimicrobial peptides. Curr. Opin. Hematol. 9, 18-22.

Levay, P. F., and Viljoen, M. (1995). Lactoferrin: a general review. Haematologica 80, 252-267.
Levy, O. (2004). Antimicrobial proteins and peptides: anti-infective molecules of mammalian leukocytes. J. Leukoc. Biol. 76, 909-925.

Lima, M. F., and Kierszenbaum, F. (1985). Lactoferrin effects on phagocytic cell function. I. Increased uptake and killing of an intracellular parasite by murine macrophages and human monocytes. J. Immunol. 134, 4176-4183.

Lincoln, J. A., Lefkowitz, D. L., Cain, T., Castro, A., Mills, K. C., Lefkowitz, S. S., Moguilevsky, N., and Bollen, A. (1995). Exogenous myeloperoxidase enhances bacterial phagocytosis and intracellular killing by macrophages. Infect. Immun. 63, 3042-3047.

Liu, K., Victora, G. D., Schwickert, T. A., Guermonprez, P., Meredith, M. M., Yao, K., Chu, F. F., Randolph, G. J., Rudensky, A. Y., and Nussenzweig, M. (2009). In vivo analysis of dendritic cell development and homeostasis. Science 324, 392-397.

Locksley, R. M., Nelson, C. S., Fankhauser, J. E., and Klebanoff, S. J. (1987). Loss of granule myeloperoxidase during in vitro culture of human monocytes correlates with decay in antiprotozoa activity. Am. J. Trop. Med. Hyg. 36, 541-548.

Mantovani, A., Cassatella, M. A., Costantini, C., and Jaillon, S. (2011). Neutrophils in the activation and regulation of innate and adaptive immunity. Nat. Rev. Immunol. 11, 519-531.

Manz, M. G., Miyamoto, T., Akashi, K., and Weissman, I. L. (2002). Prospective isolation of human clonogenic common myeloid progenitors. Proc. Natl. Acad. Sci. U.S.A. 99, 1187211877.

Marodi, L., Tournay, C., Kaposzta, R., Johnston, R. B. Jr., and Moguilevsky, N. (1998). Augmentation of human macrophage candidacidal capacity by recombinant human myeloperoxidase and granulocytemacrophage colony-stimulating factor. Infect. Immun. 66, 2750-2754.

Metcalf, D. (1989). The molecular control of cell division, differentiation commitment and maturation in haemopoietic cells. Nature 339, 27-30.

Metchnikoff, E. (1893). Lectures on the Comparative Pathology of Inflammation. London: Kegan Paul, Trench, Trubner \& Co. Ltd. 
Metchnikoff, E. (1905). Immunity in Infective Diseases. London: Cambridge University Press.

Mosser, D. M., and Edwards, J. P. (2008). Exploring the full spectrum of macrophage activation. Nat. Rev. Immunol. 8, 958-969.

Naik, S. H., Metcalf, D., van Nieuwenhuijze, A., Wicks, I., Wu, L., O'Keeffe, M., and Shortman, K. (2006). Intrasplenic steady-state dendritic cell precursors that are distinct from monocytes. Nat. Immunol. 7 , 663-671.

Naik, S. H., Sathe, P., Park, H. Y., Metcalf, D., Proietto, A. I., Dakic, A. Carotta, S., O’Keeffe, M., Bahlo, M., Papenfuss, A., Kwak, J. Y., Wu, L., and Shortman, K. (2007). Development of plasmacytoid and conventional dendritic cell subtypes from single precursor cells derived in vitro and in vivo. Nat. Immunol. 8, 1217-1226.

Nathan, C. (2006). Neutrophils and immunity: challenges and opportunities. Nat. Rev. Immunol. 6, 173-182.

Nathan, C., and Shiloh, M. U. (2000). Reactive oxygen and nitrogen intermediates in the relationship between mammalian hosts and microbial pathogens. Proc. Natl. Acad. Sci. U.S.A. 97, 8841-8848.

Nauseef, W. M. (2007). How human neutrophils kill and degrade microbes: an integrated view. Immunol. Rev. 219, 88-102.

Onai, N., Obata-Onai, A., Schmid, M. A., Ohteki, T., Jarrossay, D., and Manz, M. G. (2007). Identification of clonogenic common Flt3+M-CSFR+ plasmacytoid and conventional dendritic cell progenitors in mouse bone marrow. Nat. Immunol. 8, 1207-1216.

Parnaik, R., Raff, M. C., and Scholes, J. (2000). Differences between the clearance of apoptotic cells by professional and non-professional phagocytes. Curr. Biol. 10, 857-860.

Pluddemann, A., Mukhopadhyay, S., and Gordon, S. (2011). Innate immunity to intracellular pathogens: macrophage receptors and responses to microbial entry. Immunol. Rev. 240, 11-24.

Rabinovitch, M. (1967). "Nonprofessional" and "professional" phagocytosis: particle uptake by $\mathrm{L}$ cells and by macrophages. J. Cell Biol. 35, 108A-109A.

Rabinovitch, M. (1995). Professional and non-professional phagocytes: an introduction. Trends Cell Biol. 5, 85-87.
Rydell-Tormanen, K., Uller, L., and Erjefalt, J. S. (2006). Neutrophil cannibalism - a back up when the macrophage clearance system is insufficient. Respir. Res. 7, 143.

Sasmono, R. T., Ehrnsperger, A., Cronau, S. L., Ravasi, T., Kandane, R., Hickey, M. J., Cook, A. D. Himes, S. R., Hamilton, J. A., and Hume, D. A. (2007). Mouse neutrophilic granulocytes express mRNA encoding the macrophage colonystimulating factor receptor (CSF-1R) as well as many other macrophagespecific transcripts and can transdifferentiate into macrophages in vitro in response to CSF-1. J. Leukoc. Biol. 82, 111-123.

Savina, A., and Amigorena, S. (2007) Phagocytosis and antigen presentation in dendritic cells. Immunol. Rev. 219, 143-156.

Sawant, K. V., Cho, H., Lyons, M., Ly, L. H., and McMurray, D. N. (2010). Guinea pig neutrophil-macrophage interactions during infection with Mycobacterium tuberculosis. Microbes Infect. 12, 828-837.

Seeley, T. D. (2002). When is selforganization used in biological systems? Biol. Bull. 202, 314-318.

Segal, A. W. (2005). How neutrophils kill microbes. Annu. Rev. Immunol. 23, 197-223.

Selsted, M. E., and Ouellette, A. J. (2005). Mammalian defensins in the antimicrobial immune response. Nat. Immunol. 6, 551-557.

Serbina, N. V., Jia, T., Hohl, T. M., and Pamer, E. G. (2008). Monocytemediated defense against microbial pathogens. Annu. Rev. Immunol. 26, 421-452.

Sharma, S., Verma, I., and Khuller, G. K. (2000). Antibacterial activity of human neutrophil peptide-1 against Mycobacterium tuberculosis H37Rv: in vitro and ex vivo study. Eur. Respir. J. 16, 112-117.

Shou, W., Ram, S., and Vilar, J. M. (2007). Synthetic cooperation in engineered yeast populations. Proc. Natl. Acad. Sci. U.S.A. 104, 18771882.

Silva, M. T. (2010a). When two is better than one: macrophages and neutrophils work in concert in innate immunity as complementary and cooperative partners of a myeloid phagocyte system. J. Leukoc. Biol. 87, 93-106.

Silva, M. T. (2010b). Neutrophils and macrophages work in concert as inducers and effectors of adaptive immunity against extracellular and intracellular microbial pathogens. $J$. Leukoc. Biol. 87, 805-813.

Silva, M. T. (2011). Macrophage phagocytosis of neutrophils at inflammatory/infectious foci: a cooperative mechanism in the control of infection and infectious inflammation. J. Leukoc. Biol. 89, 675-683.

Silva, M. T., Silva, M. N., and Appelberg, R. (1989). Neutrophilmacrophage cooperation in the host defence against mycobacterial infections. Microb. Pathog. 6, 369-380.

Soehnlein, O., Kai-Larsen, Y., Frithiof, R., Sorensen, O. E., Kenne, E., Scharffetter-Kochanek, K., Eriksson, E. E., Herwald, H., Agerberth, B., and Lindbom, L. (2008a). Neutrophil primary granule proteins HBP and HNP1-3 boost bacterial phagocytosis by human and murine macrophages. J. Clin. Invest. 118, 3491-3502.

Soehnlein, O., Kenne, E., Rotzius, P., Eriksson, E. E., and Lindbom, L. (2008b). Neutrophil secretion products regulate anti-bacterial activity in monocytes and macrophages. Clin. Exp. Immunol. 151, 139-145.

Soehnlein, O., Zernecke, A., Eriksson, E. E., Rothfuchs, A. G., Pham, C. T., Herwald, H., Bidzhekov, K., Rottenberg, M. E., Weber, C., and Lindbom, L. (2008c). Neutrophil secretion products pave the way for inflammatory monocytes. Blood 112, 1461-1471.

Soehnlein, O., and Lindbom, L. (2010). Phagocyte partnership during the onset and resolution of inflammation. Nat. Rev. Immunol. 10, 427-439.

Steinman, R. M., and Banchereau, J. (2007). Taking dendritic cells into medicine. Nature 449, 419-426.

Steinman, R. M., and Swanson, J. (1995). The endocytic activity of dendritic cells. J. Exp. Med. 182, 283-288.

Sunderkotter, C., Nikolic, T., Dillon, M. J., Van Rooijen, N., Stehling, M., Drevets, D. A., and Leenen, P. J. (2004). Subpopulations of mouse blood monocytes differ in maturation stage and inflammatory response. J. Immunol. 172, 4410-4417.

Tan, B. H., Meinken, C., Bastian, M., Bruns, H., Legaspi, A., Ochoa, M. T., Krutzik, S. R., Bloom, B. R., Ganz, T., Modlin, R. L., and Stenger, S. (2006). Macrophages acquire neutrophil granules for antimicrobial activity against intracellular pathogens. J. Immunol. 177, 1864-1871.
Tauber, A. I. (2003). Metchnikoff and the phagocytosis theory. Nat. Rev. Mol. Cell Biol. 4, 897-901.

van Furth, R., Cohn, Z. A., Hirsch, J. G., Humphrey, J. H., Spector, W. G., and Langevoort, H. L. (1972). The mononuclear phagocyte system: a new classification of macrophages, monocytes, and their precursor cells. Bull. World Health Organ. 46, 845-852.

van Furth, R., Diesselhoff-den Dulk, M. C., and Mattie, H. (1973). Quantitative study on the production and kinetics of mononuclear phagocytes during an acute inflammatory reaction. J. Exp. Med. 138, 1314-1330.

Varol, C., Yona, S., and Jung, S. (2009). Origins and tissue-contextdependent fates of blood monocytes. Immunol. Cell Biol. 87, 30-38.

Volterra, M. (1927). Ricerche sul sistema reticulo-istiociterio. Lo Sperimentale. Archivio di Biologia normale e patologica 81, 319 .

Weiss, J., and Olsson, I. (1987) Cellular and subcellular localization of the bactericidal/permeabilityincreasing protein of neutrophils. Blood 69, 652-659.

Zughaier, S. M., Shafer, W. M., and Stephens, D. S. (2005). Antimicrobial peptides and endotoxin inhibit cytokine and nitric oxide release but amplify respiratory burst response in human and murine macrophages. Cell. Microbiol. 7, 1251-1262.

Conflict of Interest Statement: The authors declare that the research was conducted in the absence of any commercial or financial relationships that could be construed as a potential conflict of interest.

Received: 28 February 2012; accepted: 08 June 2012; published online: 04 July 2012. Citation: Silva MT and Correia-Neves $M$ (2012) Neutrophils and macrophages: the main partners of phagocyte cell systems. Front. Immun. 3:174. doi: 10.3389/ fimmu.2012.00174

This article was submitted to Frontiers in Microbial Immunology, a specialty of Frontiers in Immunology.

Copyright (c) 2012 Silva and CorreiaNeves. This is an open-access article distributed under the terms of the Creative Commons Attribution License, which permits use, distribution and reproduction in other forums, provided the original authors and source are credited and subject to any copyright notices concerning any third-party graphics etc. 